\title{
The NHS visitor and migrant cost recovery programme - a threat to health?
}

\author{
J. L. Potter ${ }^{1 *}$, M. Burman ${ }^{1}$, C. D. Tweed ${ }^{2}$, D. Vaghela' ${ }^{1}$ H. Kunst ${ }^{1}$, D. Swinglehurst ${ }^{1}$ and C. J. Griffiths ${ }^{1}$
}

\begin{abstract}
Background: In April 2014 the UK government launched the 'NHS Visitor and Migrant Cost Recovery Programme Implementation Plan' which set out a series of policy changes to recoup costs from 'chargeable' (largely non-UK born) patients. In England, approximately $75 \%$ of tuberculosis (TB) cases occur in people born abroad. Delays in TB treatment increase risk of morbidity, mortality and transmission in the community. We investigated whether diagnostic delay has increased since the Cost Recovery Programme (CRP) was introduced.

Methods: There were 3342 adult TB cases notified on the London TB Register across Barts Health NHS Trust between 1st January 2011 and 31st December 2016. Cases with missing relevant information were excluded. The median time between symptom onset and treatment initiation before and after the CRP was calculated according to birthplace and compared using the Mann Whitney test. Delayed diagnosis was considered greater or equal to median time to treatment for all patients (79 days). Univariable logistic regression was used to manually select exposure variables for inclusion in a multivariable model to test the association between diagnostic delay and the implementation of the CRP.

Results: We included 2237 TB cases. Among non-UK born patients, median time-to-treatment increased from 69 days to 89 days following introduction of CRP $(p<0.001)$. Median time-to-treatment also increased for the UK-born population from 75.5 days to 89.5 days $(p=0.307)$. The multivariable logistic regression model showed non-UK born patients were more likely to have a delay in diagnosis after the CRP (adjOR 1.37, 95\% Cl 1.13-1.66, $p$ value 0.001).

Conclusion: Since the introduction of the CRP there has been a significant delay for TB treatment among non-UK born patients. Further research exploring the effect of policies restricting access to healthcare for migrants is urgently needed if we wish to eliminate TB nationally.
\end{abstract}

Keywords: Policy, Healthcare access, tuberculosis, Migrant health

\section{Background}

In 2017, 1.6 million people died from world's deadliest, yet curable, infectious disease - tuberculosis (TB). TB is an infectious disease transmitted by coughing. Whilst some people become unwell straight away, some carry the infection with no symptoms for many years, this is termed latent TB infection (LTBI). People living in countries with a high incidence of TB are at higher risk

\footnotetext{
* Correspondence: Jessica.potter@qmul.ac.uk

${ }^{1}$ Centre for Primary Care and Public Health, Blizard Institute, Queen Mary University of London, London, England

Full list of author information is available at the end of the article
}

of contracting the infection that people living in places where $\mathrm{TB}$ is less common.

TB is unequally distributed; the world's poorest people bear a disproportionate burden of disease [1]. In highincome, low-incidence settings such as the UK, the majority of active TB cases occur among migrants coming from countries where $\mathrm{TB}$ is more common [2]. Countries of origin amongst foreign-born patients reflect both migrant flows and the global distribution of TB, with the highest numbers of cases amongst people from high TB-incidence regions such as South Asia and SubSaharan Africa. In the UK, evidence suggests that TB in

C The Author(s). 2020 Open Access This article is licensed under a Creative Commons Attribution 4.0 International License, which permits use, sharing, adaptation, distribution and reproduction in any medium or format, as long as you give appropriate credit to the original author(s) and the source, provide a link to the Creative Commons licence, and indicate if changes were made. The images or other third party material in this article are included in the article's Creative Commons licence, unless indicated otherwise in a credit line to the material. If material is not included in the article's Creative Commons licence and your intended use is not permitted by statutory regulation or exceeds the permitted use, you will need to obtain permission directly from the copyright holder. To view a copy of this licence, visit http://creativecommons.org/licenses/by/4.0/ The Creative Commons Public Domain Dedication waiver (http://creativecommons.org/publicdomain/zero/1.0/) applies to the data made available in this article, unless otherwise stated in a credit line to the data. 
the migrant population is largely due to reactivation of latent TB infection, originally acquired abroad $[3,4]$.

There is no internationally recognised definition of the term migrant and in other contexts it can be used to refer to an individual who has moved away from their usual place of residence to another region within a country or across international borders to another country. In this paper the term migrant is used to refer to an international migrant. With respect to this study this includes any person living within the UK who was not originally born there. This definition incorporates many different categories of migrant including but not limited to so-called 'economic migrants', refugees, asylumseekers, failed asylum-seekers and undocumented migrants.

Strategies to control TB centre around three key principles: early diagnosis; effective treatment; and preventative interventions for those at high risk (including both treatment of latent TB infection (LTBI) and BCG vaccination) [5]. The insidious, non-specific nature of symptoms associated with $\mathrm{TB}$, such as fevers and weight loss, often translate into circuitous journeys to diagnosis, involving many different healthcare providers $[6,7]$. The window of time that elapses between symptom onset and treatment is critical. If the time-to-diagnosis increases, the individual concerned is exposed to higher risk of morbidity and mortality, and, for infectious cases, the wider public is exposed to the risk of disease transmission [8-10].

Recent theoretical frameworks to describe healthcare access account for a complex and dynamic process, shaped by social interactions within particular contexts. 'Candidacy', for example, has frequently been employed to understand individuals' experiences of accessing healthcare and describes "the ways in which people's eligibility for medical attention and intervention is jointly negotiated between individuals and health services" [11, 12]. Included in this concept is the influence of "policy imperatives".

The UK National Health Service (NHS) is a taxfunded system designed to provide care, free at the point of delivery. Eligibility for free NHS healthcare is determined by the test of 'ordinary residence'; tourists and some migrants are required to pay for care [13]. Over recent years one policy imperative has been to ensure that individuals not ordinarily resident in the UK make a 'fair contribution' to the NHS. Changes in the Immigration Acts 2014 and 2016 have provided the legislative framework which has resulted in tightening of the definition of ordinary residence - the test of eligibility for free NHS care - and strengthening of mechanisms for cost recovery from chargeable individuals. Experiences of people from the Windrush generation published in mainstream media between 2017 and 2018 illuminated the broader impact of these policies: Individuals denied access to treatment such as chemotherapy because they could not demonstrate eligibility for free NHS care.

The health service in the UK is devolved; the policies discussed in this paper are specific to England. The NHS Visitor and Migrant Cost Recovery Programme (CRP), introduced in April 2014, was designed to ensure migrants in England who are otherwise ineligible for free NHS care make a 'fair contribution' [14] to the cost of running the NHS. Policies such as this may play an important role in shaping patients' experiences of healthcare access $[11,12,15,16]$.

The CRP was supported by changes to legislation including the Immigration Act 2014 which increased the recoverable cost of treatment from $100 \%$ of tariff to $150 \%$ for ineligible residents from outside the European Economic Area. The 'roll-out' incorporated a range of new activities: strengthening of overseas visitor manager teams; more targeted strategies for the identification of ineligible service-users; introduction of punitive sanctions for NHS Trusts who failed to implement CRP measures robustly; and incentives enabling the recovery of increased tariffs from patients [17] (Fig. 1). House of Commons transcripts on this issue at the time [18], along with supporting policy documents [14] detail the need for a 'change in culture' such that determinations of eligibility and charging should become business-asusual within the NHS.

Barts Health NHS Trust serves three East London boroughs and treats over 500 patients with a diagnosis of active TB each year. This represents approximately $10 \%$ of cases in England. National data is collected on all TB cases and includes: time between symptom onset and start of treatment; country of birth; and year of entry to the UK. Beyond these, migrant subgroups are not further classified and, in particular, immigration status and eligibility for free NHS care are not recorded. This study uses routinely collected surveillance data to examine time to treatment onset among UK-born and non-UK born populations in this region, before and after implementation of the CRP.

\section{Methods}

The London TB Register (LTBR) is an online database for the statutory recording of notified cases of TB, as entered by clinical staff. The database contains details of patient ethnicity; gender; age; place of birth; length of time resident in the UK; date of symptom onset; date TB treatment started; occupation; and other medical history. We collected patient data from the LTBR for TB cases notified across Barts Health NHS Trust between 2011 and 2016 inclusive. We included all adult cases $(\geq 18$ years old) that did not have any missing relevant data. 


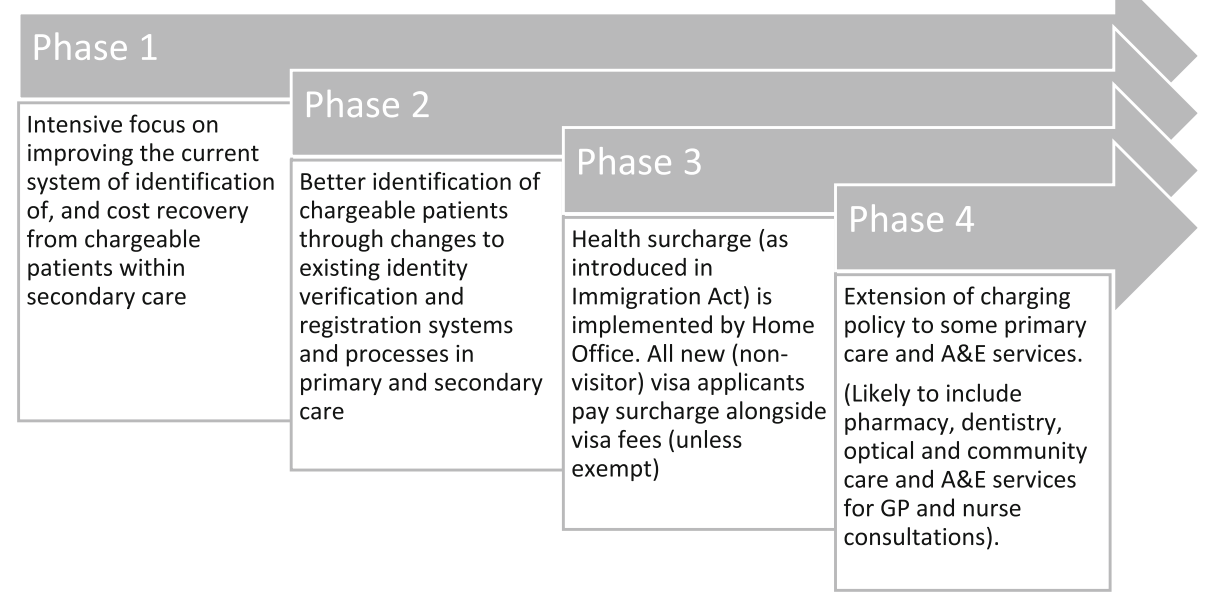

Fig. 1 Phased approach reproduced from the Visitor \& Migrant Cost Recovery Programme Implementation Plan 2014-2016

We manually reviewed the dataset and categorised patients for the analysis as follows. Time in the UK was categorised as $0-1$ years, $2-5$ years, 6-10 years, or $11+$ years. Patient occupation was classified using Office of National Statistics guidance as "managerial", "intermediate", "unskilled", "unemployed", "housewife/ house husband", "student", "unknown", or "retired" [19]. We identified patients as having either "no social risk factors" or "at least one social risk factor" based on the additional information on the LTBR. Social risk factors are relevant to adherence rather than risk of infection, although there is clearly some overlap, and included: history of incarceration; drug or alcohol dependence; homelessness; and mental health concerns.

We identified patients as either "pre-CRP" or "postCRP" according to the date they started their treatment for TB (before or after 1st April 2014, respectively). April 1st 2014 was the date provided in the policy. It signifies a conservative estimate of the beginning of the implementation of a complex series of policies and practices designed to restrict healthcare access for some groups of people not born in the UK. We also categorised patients as either "UK-born" or "not UK-born" based on place of birth data in the LTBR. In 59 cases, there was no data on treatment start date recorded in the LTBR database. For these cases we used the date the patient was first seen in TB clinic as a proxy measure.

\section{Statistical analysis}

All data handling and statistical analyses were performed using Stata version 15 (StataCorp, Texas). Statistical significance was set at $5 \%$ for all tests. The median time to treatment was selected as the outcome of interest due to a combination of robustness against outliers, a lack of normal distribution in the time to treatment data, and simplicity of understanding. The Chi square test was used to compare the proportion of patients UK-born or not UK-born with each baseline characteristic when grouped as pre-CRP and post-CRP.

The time-to-treatment was calculated for all patients as the number of days between the date of symptom onset and the date of starting treatment. The MannWhitney test was used to compare the median time to treatment for all patients before and after the CRP. The difference in time to treatment before and after the CRP was then compared for patients according to their status as 'UK-born' or 'born outside the UK', again using the Mann-Whitney test.

We defined 'delayed diagnosis' as any patient with a time to treatment greater than the median value for all patients. We defined delay in this way because there is no established definition of what constitutes a delayed diagnosis of TB available in the literature [8]. In addition healthcare access is highly contextual and so applying alternative conceptions of delay from other regions or countries would not be appropriate. The proportion of all patients with a 'delayed diagnosis' before and after the CRP was investigated using the Chi square test, followed by patients according to their UK-born status. Assumptions relating to the Chi-square test, including minimum number for expected value per cell, were found to have been met.

Logistic regression was used to investigate the relationship between diagnostic delay (as a binary outcome) and whether date of diagnosis was before or after the CRP for patients born outside the UK. Variables were manually selected based on significance level in a univariable model $(p$ value $<0.10)$ with the exposure (treatment before or after the CRP) and outcome variables (delay in diagnosis). These were included, along with sex 
and age, in a final multivariable logistic regression model testing the association between delay in diagnosis and introduction of the CRP to account for potential confounding. The regression model was tested using the Hosmer-Lemeshow test, and the minimum number of measurements was thought to have been reached in each of the two patient groups based on the number of variables being tested.

\section{Results}

A total of 3342 cases were added to the LTBR between January 2011 and December 2016. There were 2237 cases were included in the final analysis (see Table 1). The median time to treatment for all included patients was 79 days. In the time period prior to the introduction of the CRP the median time to treatment was 70 days for all patients and this increased to 89 days after the CRP was introduced ( $p$ value $<0.001$ ).

Of note, significantly more UK-born patients had more than one social risk factor compared with non-UK born patients (Chi-squared $p<0.001)$. There was also a significant increase in the number of years migrant patients had been living in the UK before their diagnosis with TB pre-CRP (10 years) and post-CRP (14.8 years, Chisquared $p$ value $\mathrm{p}<0.001$ ).

There was a significant increase in the time-totreatment for non-UK born patients following the implementation of the CRP (see Table 2 and Fig. 2). Pre-CRP, the median time to treatment was 69 days in this group, increasing to 89 days post-CRP ( $p$ value $<0.0001$ ). There was also an increase in the median time to treatment for UK-born patients post-CRP ( 75.5 days vs 89.5 days) but this increase was not significant $(p=0.307)$. The proportion of patients categorised as having a delayed diagnosis according to place of birth and CRP timing are shown in Table 3.

After univariable analysis the following variables had associated $p$ values $<0.10$ and were included as exposure variables to adjust for confounding in the final multivariable logistic regression model due to a $p$ value $>0.10$ :
Table 2 Median time to diagnosis before/after the CRP for all patients, and then stratified by UK-born status

\begin{tabular}{llr}
\hline Patient group & Median time to diagnosis (days) & $p$ value \\
\hline All & 70 & 0.001 \\
Before-CRP & 89 & \\
$\begin{array}{l}\text { After-CRP } \\
\text { UK-born }\end{array}$ & & \\
Before-CRP & 75.5 & 0.307 \\
After-CRP & 89.5 & \\
Non-UK Born & & $<0.001$ \\
Before-CRP & 69 & \\
After-CRP & 89 & \\
\hline
\end{tabular}

CRP Cost Recovery Program

patient age; gender; time in the UK (as a categorical variable); and the presence of one or more social risk factors for TB. We excluded the following variables from the model: being born in an English-speaking country, site of $\mathrm{TB}$ disease, previous $\mathrm{TB}$ and being a healthcare worker because no association was found on univariate analysis.

Table 4 shows the results from the multivariable logistic regression analysis for patients born outside the UK. There was a significant association with treatment delay from the onset of symptoms in a multivariable logistic regression model (adjusted OR 1.37, 95\% CI 1.13-1.66, $p$ value $<0.01)$ among this group. Increasing age was also positively associated with treatment delay for patients born outside the UK. Conversely, the presence of one or more social risk factors was negatively associated with a treatment delay. The Hosmer-Lemeshow goodness-of-fit test was not statistically significant ( $p=$ 0.4596 ) suggesting the model is consistent and adequate to explain the observed outcome.

\section{Discussion}

In 2016 the average time between symptom onset and starting treatment for pulmonary TB in England was 77

Table 1 Baseline characteristics for patients diagnosed before and after CRP based on UK-born status

\begin{tabular}{|c|c|c|c|c|}
\hline & \multicolumn{2}{|l|}{ Pre-CRP } & \multicolumn{2}{|l|}{ Post-CRP } \\
\hline & UK born & Non-UK born & UK born & Non-UK born \\
\hline Total cases & 166 & 1037 & 170 & 864 \\
\hline Median age (IQR) & $32.0(23-46)$ & $32.0(26-45)$ & $33.5(25-47)$ & $37.0(29-49)$ \\
\hline \multicolumn{5}{|l|}{ Sex } \\
\hline Female (\%) & 43.5 & 36.9 & 32.5 & 37.5 \\
\hline Male (\%) & 56.5 & 63.1 & 77.5 & 62.5 \\
\hline Pulmonary TB Cases (\% Smear Positive) & $109(45.87)$ & $428(36.5)$ & $101(31.7)$ & $367(33.9)$ \\
\hline Extra-pulmonary TB cases (\% of total cases) & $61(35.6)$ & $609(58.7)$ & $65(39.2)$ & $497(57.5)$ \\
\hline$\%$ with $\geq 1$ social risk factors & 20.0 & 6.5 & 18.7 & 7.6 \\
\hline
\end{tabular}



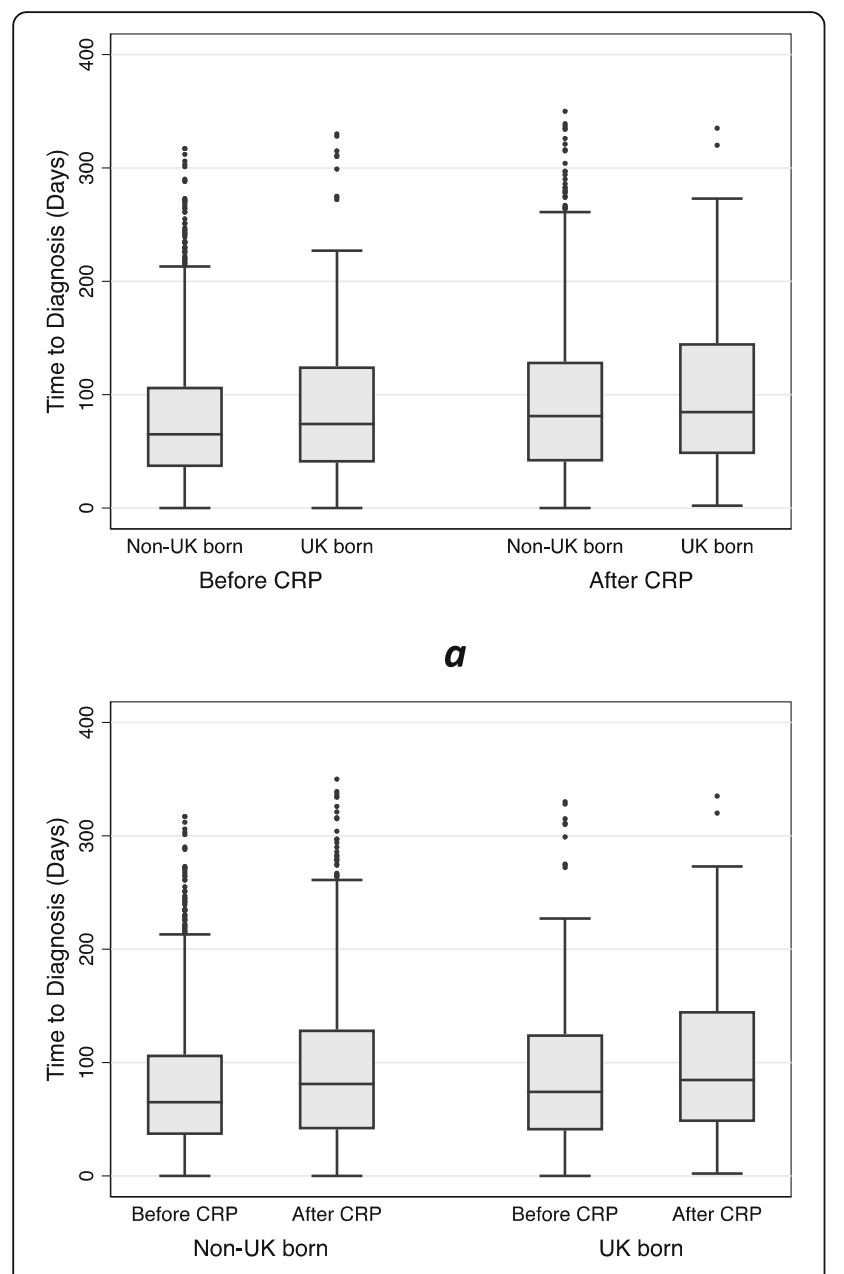

b

Fig. 2 Boxplot showing time to diagnosis (in days) by a) whether patients were treated before or after the introduction of the Cost Recovery Program (CRP), sub-catergorised by place of birth and by b) place of birth, before and after the introduction of the CRP. Times to diagnosis above 350 days have not been displayed. Time to diagnosis: days from onset of symptoms to starting treatment

days [2]. A key aim of Public Health England and NHS England's Collaborative Tuberculosis Strategy is to "improve access to services and ensure early diagnosis" [20]. This study has identified that, since the implementation of the CRP, migrants in East London are more likely to experience delay in treatment of their TB. This is an important finding since the longer the delay in diagnosing $\mathrm{TB}$, the greater the morbidity [21] and mortality [22] for the individual, and the greater the risk of transmission in the community [23].

There are a number of potential mechanisms at play which may be relevant in the association between the experiences of migrants accessing healthcare and health policies that restrict access to care based on immigration status $[11,12]$. There is already evidence to show that migrants in the UK are often not aware of their entitlements to care [24]. This is further complicated by recent legislative changes that have altered who is eligible for care and who is not, including the introduction of an immigration health surcharge that accompanies visa applications [25]. Previous research has shown patients' concerns about being charged for care delay healthseeking, even before a diagnosis has been made [26-28]. This is important because diagnosis and treatment of TB, like many other infectious diseases, is exempt from charging in the UK, regardless of immigration status [29]. Crucially, however, patients present with undifferentiated symptoms - not a diagnosis - and many may be unaware of the details of the regulations [30].

Recent evidence suggests the CRP is just one policy among several which constitute a broader 'hostile environment' aimed at people living in the UK illegally [31]. For example a data-sharing agreement between NHS Digital and the Home Office $[32,33]$ requires that NHS staff report people with an outstanding bill exceeding $£ 500$ to the Home Office. Significant sharing of patients' demographic information between the NHS and the Home Office has been reported [34].

The 'hostile environment' is an important sociopolitical context within which people make decisions about seeking help, including decisions regarding whether and how they identify themselves as a candidate for health care [35]. This effect may be independent of their legal eligibility for free care. Fear as a deterrent to healthcare access among migrants has been well documented in several countries including the UK $[24,36]$. In 2012 the government made clear their explicit intention to create a "really hostile environment" for those living in the UK without the legal right to do so

Table 3 Proportions of UK-born and Non-UK born patients with a recorded delay in diagnosis before and after the introduction of the CRP. Delay in diagnosis is greater than or equal to median time (79 days) for all patients. Row percentages shown for proportions of patients with diagnostic delay

\begin{tabular}{lllll}
\hline Place of birth & Delay in Diagnosis & Delay (Row \%) & No Delay (Row \%) & $P$ value \\
\hline UK-Born & Pre-CRP & $82(48.2)$ & $88(51.8)$ & $75(45.2)$ \\
Non-UK Born & Post-CRP & $91(54.8)$ & $575(55.5)$ \\
& Pre-CRP & $462(44.6)$ & $387(44.8)$ \\
\hline
\end{tabular}


Table 4 Results of the multivariable logistic regression model with exposure variables shown as rows. Odds ratios relate to the binary outcome variable of diagnostic delay (greater than or equal to median time to diagnosis). Results shown are only for patients born outside the UK. Social risk factors for TB included history of alcohol dependence, recreational drug use, homelessness or imprisonment

\begin{tabular}{lll}
\hline & $\begin{array}{l}\text { Adjusted Odds Ratio } \\
\text { (95\% confidence interval) }\end{array}$ & $p$ value \\
\hline Treatment after CRP & $1.37(1.13-1.66)$ & 0.001 \\
Age & $1.01(1.00-1.02)$ & 0.010 \\
Sex & $1.13(0.92-1.40)$ & 0.245 \\
Time in the UK & REFERENCE & \\
0-1 year & $1.05(0.77-1.43)$ & $\mathrm{n} / \mathrm{a}$ \\
2-5 years & $0.96(0.68-1.36)$ & 0.779 \\
6-10 years & $1.14(0.81-1.59)$ & 0.834 \\
11+ years & & 0.452 \\
Occupation & REFERENCE & $\mathrm{n} / \mathrm{a}$ \\
managerial/professional & $0.86(0.54-1.35)$ & 0.512 \\
Intermediate & $0.82(0.52-1.30)$ & 0.405 \\
Unskilled & $0.73(0.46-1.16)$ & 0.182 \\
Unemployed & $0.74(0.44-1.24)$ & 0.253 \\
Housewife/Househusband & $0.62(0.38-1.02)$ & 0.061 \\
Student & $0.59(0.32-1.09)$ & 0.089 \\
Unknown & $0.43(0.23-0.78)$ & 0.006 \\
Retired & $0.76(0.61-0.96)$ & 0.019 \\
\hline or more social risk factor for TB & & \\
\hline
\end{tabular}

[37]. Aside from the CRP, other measures included: a rise in immigration raids; the prospect of unlimited detention; the threat to health and even life that immigration detention poses [38, 39]; school meals withheld because of parents' immigration status [40], restrictions to the housing rental market, driving licenses and bank accounts in similar ways to the restrictions applied to the NHS [41]. The influence of these other 'hostile environment' policies have not been accounted for within this study but may have contributed to the overall findings.

There are other contemporaneous policy-related contexts which may be relevant to the increase in time to treatment reported in this study. Access to translation services have changed due to imposed cuts under conditions of austerity. Across the NHS, staffing levels decreased and waiting times for hospital care increased during the study period amidst concerns of an NHS in crisis' [42]. It is important to consider whether local changes in service provision may have impacted the results. The study data is collected from three London boroughs each served by a hospital with an A\&E and local respiratory and TB services. Whilst there was an increased focus on TB among migrants during the study period, including education and awareness raising in primary care and local communities, no other major service changes occurred during this time. Finally, as with all observational analyses, causal associations cannot be inferred between the implementation of the CRP and the significant increase in the time to diagnosis.

Our study shows the UK-born population experienced a non-significant increase in the time to treatment of TB. A significantly higher proportion of UK-born patients had one or more social risk factors compared with those not born in the UK. This is reflective of national data [2]. Therefore the UK-born population is potentially more vulnerable to the effects of austerity; health suffers whilst individuals manage other competing priorities such as employment, housing, and limited income (earned or through welfare) restricting their means to access care [43]. This would result in an underestimation of effect. Conversely, clinicians' sensitivity to TB as a differential diagnosis is likely to be heightened among patients with particular risk factors such as homelessness. However, not being born in the UK - particularly individuals from high TB incidence countries - is also likely to increase alertness amongst clinicians to the possibility of a TB diagnosis.

Nevertheless, these factors do not explain why only the non-UK born population experienced a significant delay in time to diagnosis and treatment following the introduction of the CRP whilst the UK-born population did not. Of note, migrants diagnosed with TB after 2014 had been in the UK significantly longer than those diagnosed before. There may be a number of reasons for this such as changes to immigration policies and the introduction of pre-entry TB screening [44]. Nonetheless, 'newness' of migrants has been associated with increased difficulty accessing care $[35,45]$ potentially resulting in an under estimation of the effect size.

Whilst the study area is geographically small, it accounts for approximately $10 \%$ of all cases of $\mathrm{TB}$ in the UK during the research period [2]. TB in the UK is largely focused in urban areas with large migrant communities. Thus it is possible our findings may be applicable to other areas within England which have similar migrant populations and have been subject to similar policies designed to restrict access to healthcare for some migrants and visitors. However, this study does not demonstrate causality and further research is required to examine the nature of the relationship between different categories of migrant, their eligibility for free NHS care and the complex and evolving arena of laws, policies and practices which shape access to TB treatment.

There are a number of limitations to the study. This paper does not claim causality but nevertheless 
demonstrates an important association that warrants further investigation. The ability to communicate in the language of the host country has been shown to affect healthcare access as well as the quality of care received by migrants [46], however English language ability is not routinely collected. Immigration status has also been shown to affect healthcare access [47] but is not routinely collected. It was therefore not possible to differentiate between migrants eligible for free NHS care and those who are not. Socio-economic status was determined through a proxy measure - occupational status which has well-documented limitations [48]. A binary cut-off before and after the CRP does not reflect the reality of a policy which was rolled out over subsequent years. The unbalanced nature of the numbers in the UKborn and non-UK-born groups should not have introduced bias to the tests for significance used here but could have had an impact on the power of these tests to detect significant differences. One potential way to try to address this asymmetry in future work could be to employ matching, however careful thought would have to go into the selection of matching criteria. There are other techniques that could have been used to analyse the data that would account for the longitudinal nature the dataset, such as an interrupted time series analysis. However, this would introduce additional assumptions such as linearity of the data, predictable change in timevarying external factors, and autocorrelation. The findings presented here merely suggest an association with time as a binary variable using a simple test of proportion.

\section{Conclusion}

This research demonstrates a significant association between diagnostic delay for patients with $\mathrm{TB}$ who were not born in the UK and policies which restrict healthcare access to visitors and migrants not entitled to free NHS care. Whilst there is little evidence of TB transmission outside of migrant communities [49], it remains the case that policies which limit access to healthcare for particular populations have significant implications not only for the health of these individuals but that of the general public. In the case of TB in England, and applicable to other low TB-burden countries where the majority of cases occur among migrants, restricting healthcare access for this population undermines national efforts to eliminate TB. Finally, as the recent UCL-Lancet commission on migration and health highlights, governments have a "moral and legal obligation" to uphold the right to the highest attainable standard of health for all people, no matter their immigration status [16].

\section{Abbreviations}

BCG: Bacillus Calmette-Guérin vaccine; CRP: NHS Visitor and Migrant Cost Recovery Programme; LTBI: Latent Tuberculosis Infection; LTBR: London
Tuberculosis Register; NHS: National Health Service; TB: Tuberculosis; UK: United Kingdom

\section{Acknowledgements}

The authors acknowledge the TB section at Public Health England (PHE) for maintaining the London TB Register (LTBR) and the healthcare workers involved in data collection for LTBR.

\section{Authors' contributions}

JP conceived of the study, contributed to analysis and wrote the first draft of the paper. MB and CDT undertook data analysis and drafting the manuscript. DV collected preliminary data and contributed to manuscript. HK, DS and

CJG provided supervision and contributed to later drafts of the manuscript.

All authors read and approved the final manuscript.

\section{Funding}

JP was fully funded by the Medical Research Council as part of a strategic skills doctoral research fellowship, grant number MR/M014517/1. The MRC played no role beyond that of funder in the production of this research article.

\section{Availability of data and materials}

Data used in this study is held by Public Health England and was accessed via the London Tuberculosis Register with their permission. The datasets used and/or analysed during the current study are available from the corresponding author on reasonable request with permission from the London Tuberculosis Register.

\section{Ethics approval and consent to participate}

The data from this study is routinely collected locally as part of the Enhanced National TB Surveillance Registry which is hosted by Public Health England who has authority under the Health and Social Care Act 2012 to hold and analyse national surveillance data for public health and research purposes [50].

\section{Consent for publication}

Not applicable.

\section{Competing interests}

$J P$ is a member of several grass roots organisations that campaign for the health rights of migrants including Medact and Docs Not Cops. No other authors have competing interests to declare.

\section{Author details}

${ }^{1}$ Centre for Primary Care and Public Health, Blizard Institute, Queen Mary University of London, London, England. ${ }^{2}$ MRC Clinical Trials Unit, University College London, London, England.

Received: 18 July 2019 Accepted: 13 March 2020

Published online: 20 April 2020

\section{References}

1. Farmer P. Social scientists and the new tuberculosis. Soc Sci Med. 1997; 44(3):347-58 [Cited 2015 Mar 12]. Available from: http://www.ncbi.nlm.nih. gov/pubmed/9004369.

2. Public Health England. Tuberculosis in England 2017 Report. 2017; Version 1.: 173.

3. Kruijshaar M, Abubakar I, Stagg HR, Pedrazzoli D, Lipman M. Migration and tuberculosis in the UK: targeting screening for latent infection to those at greatest risk of disease. Thorax. 2013;68(12):1172-4 Available from: http:// linker2.worldcat.org/?rft.institution_id=129730\&spage=1172\&pkgName= freeart\&issn=0040-6376\&linkclass=to_article\&jKey=thorax.bmj.com\&issue=12 \&provider=highwire\&date $=2013-12$ \&aulast $=$ Kruijshaar+ME\%3B + Abubakar + $1 \% 3 B+$ Stagg+HR\%3B+Pedrazzoli+D\%3B+Lipman+M\&at.

4. Walker M, Lalor K, Broda A, Saldana Luisa O, Morgan M, Parker L, et al. Assessment of Mycobacterium tuberculosis transmission in Oxfordshire, UK, 2007-12, with whole pathogen genome sequences: an observational study. Lancet Respir Med. 2014;2(4):285-92 Available from: http://linker2.worldcat. org/?rft.institution id $=129730 \&$ spage $=285 \& p k g$ Name $=$ ckjournalathens\&issn= 2213-2600\&linkclass=to_article\&jKey $=22132600 \& i s s u e=4 \&$ provider $=$ 
elsevier\&date $=2014-04$ \&aulast $=$ Walker+T.M.\%3B+Golubchik+T.\%3B+Giess+A. P.\%3B+Del+Ojo+Elias+C.\%3B+Walke.

5. WHO. Global Tuberculosis Report 2017: World Heal Organ; 2017. p. 1-262. Available from: http://apps.who.int/iris/bitstream/10665/259366/1/ 9789241565516-eng.pdf?ua=1.

6. Boudioni M, Mclaren S, Belling R, Woods L. Listening to those on the frontline: service users' experiences of London tuberculosis services. Patient Prefer Adherence. 2011;5:267-77 [Cited 2013 Nov 12]. Available from: http:// www.pubmedcentral.nih.gov/articlerender.fcgi?artid=3140309\&tool= pmcentrez\&rendertype $=$ abstract.

7. Lad TS, Packe GE. Tuberculosis: a missed opportunity for early diagnosis at the front line? Emerg Med J. 2014;31(11):942-3 [Cited 2016 Aug 5]. Available from: http://www.ncbi.nlm.nih.gov/pubmed/24150814.

8. Storla DG, Yimer S, Bjune GA. A systematic review of delay in the diagnosis and treatment of tuberculosis. BMC Public Health. 2008;8, 15(1) [Cited 2014 Nov 10]. Available from: http://linker2.worldcat.org/?frt.institution_id=12973 0\&pkgName=UKPMC\&linkclass=to_article\&jKey=445\&provider=NLM\&date $=$ 2008\&aulast=Storla+D.G.\%3B+Yimer+S.\%3B+Bjune+G.A.\&atitle=A+ systematic+review+of+delay+in+the+diagnosis+and+treatment+of+ tuberculosis\&title.

9. Leung ECC, Leung CC, Tam CM. Delayed presentation and treatment of newly diagnosed pulmonary tuberculosis patients in Hong Kong. Hong Kong Med J. 2007;13(3):221-7 [Cited 2016 Aug 5]. Available from: http:// www.ncbi.nlm.nih.gov/pubmed/17548911.

10. Potter JL, Inamdar L, Okereke E, Collinson S, Dukes R, Mandelbaum M. Support of vulnerable patients throughout TB treatment in the UK. J Public Health (Bangkok). 2015:1-5 Available from: http://jpubhealth.oxfordjournals. org/cgi/doi/10.1093/pubmed/fdv052.

11. Dixon-Woods M, Cavers D, Agarwal S, Annandale E, Arthur A, Harvey J, et al. Conducting a critical interpretive synthesis of the literature on access to healthcare by vulnerable groups. BMC Med Res Methodol. 2006;6(1):35 [Cited 2015 Feb 11]. Available from: http://www. biomedcentral.com/1471-2288/6/35.

12. Chase LE, Cleveland J, Beatson J, Rousseau C. The gap between entitlement and access to healthcare: an analysis of "candidacy" in the help-seeking trajectories of asylum seekers in Montreal. Soc Sci Med. 2017;182:52-9 Available from: https://inkinghub.elsevier.com/retrieve/pii/ S0277953617301946.

13. Blundell D. NHS Charging and Eligibility: The Position of Overseas Visitors: Landmark Chambers; 2014. [Cited 2018 May 4]; Available from: http://www. landmarkchambers.co.uk/userfiles/documents/resources/David BlundellNHSChargingandEligibility-The PositionofOverseasVisitors.pdf.

14. Department of Health. Making a fair contribution: Government response to the consultation on the extension of charging overseas visitors and migrants using the NHS in England. 2017 [Cited 2017 Apr 24]. Available from: https:/www.gov.uk/government/uploads/system/uploads/ attachment_data/file/590027/Cons_Response_cost_recovery.pdf.

15. Malmusi D, Drbohlav D, Dzúrová D, Palència L, Borrell C. Inequalities in healthcare access by type of visa in a context of restrictive health insurance policy: the case of Ukrainians in Czechia. Int J Public Health. 2014t;59(5):7159 Available from: http://link.springer.com/10.1007/s00038-014-0592-4.

16. Abubakar I, Aldridge RW, Devakumar D, Orcutt M, Burns R, Barreto ML, et al. The lancet commissions the UCL - lancet commission on migration and health : the health of a world on the move. Lancet. 2018;392:2606-54.

17. Department of Health. Visitor and Migrant NHS Cost Recovery Programme: Implementation Plan 2014-16. 2014 [Cited 2016 Aug 16]. Available from: https://www.gov.uk/government/uploads/system/uploads/attachment_ data/file/329789/NHS_Implentatation_Plan_Phase_3.PDF.

18. House of Commons Committee of Public Accounts. NHS treatment for overseas patients. Thirty-seventh Report of Session 2016-17. 2017. Available from: https://www.publications.parliament.uk/pa/cm201617/cmselect/ cmpubacc/771/771.pdf.

19. Office for National Statistics. Volume 3: The National Statistics Socioeconomic Classification: (Rebased on the SOC2010) User Manual. Standard Occupational Classification 2010, vol. 3; 2010. p. 70. [Cited 2018 Aug 6]. Available from: https://www.ons.gov.uk/methodology/ classificationsandstandards/standardoccupationalclassificationsoc/soc2010/ soc2010volume3 thenationalstatisticssocioeconomicclassificationnssecrebasedonsoc2010.

20. Public Health England. Collaborative Tuberculosis Strategy for England, 2015 to 2020. London: GOV.UK; 2015.
21. Virenfeldt J, Rudolf F, Camara C, Furtado A, Gomes V, Aaby P, et al. Treatment delay affects clinical severity of tuberculosis: a longitudinal cohort study. BMJ Open. 2014;4(6):e004818 [Cited 2017 Mar 9]. Available from: http://www.ncbi.nlm.nih.gov/pubmed/24916087.

22. Zahar JR, Azoulay E, Klement E, De Lassence A, Lucet JC, Regnier B, et al. Delayed treatment contributes to mortality in ICU patients with severe active pulmonary tuberculosis and acute respiratory failure. Intensive Care Med. 2001;27(3):513-20 [Cited 2017 Mar 9]. Available from: http://www.ncbi. nlm.nih.gov/pubmed/11355119.

23. Golub JE, Bur S, Cronin WA, Gange S, Baruch N, Comstock GW, et al. Delayed tuberculosis diagnosis and tuberculosis transmission. Int J Tuberc Lung Dis. 2006;10(1):24-30 [Cited 2014 Apr 8]. Available from: http://www. ncbi.nlm.nih.gov/pubmed/16466033.

24. Poduval S, Howard N, Jones L, Murwill P, Mckee M, Legido-Quigley H. Experiences among undocumented migrants accessing primary care in the United kingdom: a qualitative study. Int J Health Serv. 2015;45(2):320 [Cited 2015 May 13]. Available from: http://joh.sagepub.com/content/early/2015/ 02/12/0020731414568511.abstract.

25. Potter JL. Patients not passports - no borders in the NHS! Justice. Power Resist. 2018;2(2):417-29 Available from: http://www.egpress.org/ Docs-Not-Cops.

26. Weaver KE, Rowland JH, Bellizzi KM, Aziz NM. Forgoing medical care because of cost. Cancer. 2010;116(14):3493-504 Available from: http://doi. wiley.com/10.1002/cncr.25209.

27. Quy J. What are the experiences of vulnerable migrants when accessing secondary healthcare in the United Kingdom? 2017 [Cited 2018 Aug 10]. Available from: https://www.doctorsoftheworld.org.uk/Handlers/Download. ashx?!DMF=8f735eb1-d357-4df5-9723-cf7081bda719.

28. Ockert-Axelsson H. Sick and tired, and afraid: Assessing the relationship between unpaid hospital bills and the consequences debt can have on immigration status for undocumented migrants at an East London charity clinic. [Cited 2018 Aug 10]; Available from: https://www. doctorsoftheworld.org.uk/Handlers/Download.ashx?!DMF=c5e794a1-8c3 0-4457-a096-2da02fd14ed0.

29. Department of Health. Guidance on implementing the overseas visitor charging regulations. 2017 [Cited 2018 Feb 2]. Available from: www. nationalarchives.gov.uk/doc/open-government-licence/.

30. Potter J, White V, Swinglehurst D, Griffiths C. Did migrants with tuberculosis in the UK know their condition was exempt from charges? Eur J Pub Health. 2018;28(suppl_1):cky048.146. https://doi.org/10.1093/eurpub/cky048.146.

31. Yuval-Davis N, Wemyss G, Cassidy K. Everyday Bordering, Belonging and the Reorientation of British Immigration Legislation. Sociology. 2017;52(2):228 [Cited 2017 Oct 10]. Available from: http://journals.sagepub.com/doi/10.11 77/0038038517702599.

32. Home Office, Department of Health, NHS Digital. Memorandum of Understanding. UK Government. 2016 [Cited 2017 Mar 9]. Available from: https://www.gov.uk/government/uploads/system/uploads/attachment_ data/file/585928/MOU_v3.pdf.

33. Potter J. Border control in a healthcare setting is not in the public's best interests. J Public Health (Bangkok). 2017;39(2):219-20 Available from: https://academic.oup.com/jpubhealth/article-lookup/doi/10.1093/ pubmed/fdx051.

34. Travis A. NHS hands over patient records to Home Office for immigration crackdown. Guardian. 2017; Available from: https://www.theguardian.com/ uk-news/2017/jan/24/nhs-hands-over-patient-records-to-home-office-forimmigration-crackdown.

35. Dixon Woods M, Kirk D, Agarwal S, Annandale E, Arthur T, Harvey J, et al. Vulnerable groups and access to health care: a critical interpretive review. Report for the National Co-ordinating Centre for NHS Service Delivery and Organisation R \& D (NCCSDO). 2005. Available from: http://gohealthlive. com/files/images/SDOvulnerablegroups2005.pdf.

36. Asch S, Leake B, Gelberg L. Does fear of immigration authorities deter tuberculosis patients from seeking care? West J Med. 1994;161(4):373-6.

37. Kirkup J, Winnett R. Theresa May interview: 'We're going to give illegal migrants a really hostile reception'. The Telegraph. 2012 [Cited 2018 Feb 2]; Available from: http://www.telegraph.co.uk/news/uknews/immigration/92 91483/Theresa-May-interview-Were-going-to-give-illegal-migrants-a-reallyhostile-reception.html.

38. Canning V. The Multiple Forms of Violence in the Asylum System. In: Cooper V, Whyte D, editors. The Violence of Austerity: Pluto Press; 2017. p. 67-74. [Cited 2018 May 10]. Available from: http://oro.open.ac.uk/50655/. 
39. Campbell R. Locked up, locked out: health and human rights in immigration detention; 2017.

40. Weale S. Children "denied free school meals because of parents" immigration status'. The Guardian. 2018; Available from: https://www. theguardian.com/education/2018/may/09/children-denied-free-schoolmeals-because-of-parents-immigration-status.

41. Home Office. Sanctions : refer case to Interventions and Sanctions Directorate ( ISD ); 2018. p. 1-38.

42. Dayan M, Ward D, Gardner T, Elain K. How good is the NHS? 2018

43. Maslow AH. A Theory of Human Motivation. Psychol Rev. 1943;50:270-396 [Cited 2018 Aug 10]. Available from: https://s3.amazonaws.com/academia. edu.documents/34195256/A_Theory_of_Human_Motivation_-_Abraham_H_ Maslow_-_Psychological_Review_Vol_50_No_4_July_1943. pdf?AWSAccessKeyld=AKIAIWOWYYGGZYY53UL_3A\&Expires=1533913564 \&Signature=FAy711\%2FarddnZggP7ordwb8UOiY\%3D\&res.

44. Thomas HL, Harris RJ, Muzyamba MC, Davidson JA, Lalor MK, Campbell CNJ, et al. Reduction in tuberculosis incidence in the UK from 2011 to 2015: A population-based study. Thorax. 2018;73(8):769-75 Available from: http:// www.ncbi.nlm.nih.gov/pubmed/29674389.

45. Rashid A, Jagger C. Attitudes to and perceived use of health care services among Asian and non-Asian patients in Leicester. $\mathrm{Br} J$ Gen Pract. 1992;42(358):197-201 Available from: http://www.ncbi.nlm.nih.gov/ pubmed/1389431.

46. Westwood J, Howard LM, Stanley N, Zimmerman C, Gerada C, Oram S Access to, and experiences of, healthcare services by trafficked people: findings from a mixed-methods study in England. Br I Gen Pract. 2016; 66(652): $794-801$.

47. Jayaweera $\mathrm{H}$. Health and access to health care of migrants in the UK. Better Heal Brief; 2010

48. Galobardes B, Shaw M, Lawlor DA, Lynch JW, Davey Smith G. Indicators of socioeconomic position (part 1). J Epidemiol Community Health. 2006;60(1): 7-12 Available from: http://www.ncbi.n/m.nih.gov/pubmed/16361448.

49. Aldridge RW, Zenner D, White PJ, Muzyamba MC, Dhavan P, Mosca D, et al. Tuberculosis in migrants moving from high-incidence to low-incidence countries: a population-based cohort study of 519955 migrants screened before entry to England, Wales, and Northern Ireland. Lancet. 2016; 388(10059):2510-8 Available from: http://linkinghub.elsevier.com/retrieve/ pii/S014067361631008X.

50. GOV.UK. Health and Social Care Act 2012. 2012. 17(13). Available from: http://www.legislation.gov.uk/ukpga/2012/7/section/17.

\section{Publisher's Note}

Springer Nature remains neutral with regard to jurisdictional claims in published maps and institutional affiliations.

Ready to submit your research? Choose BMC and benefit from:

- fast, convenient online submission

- thorough peer review by experienced researchers in your field

- rapid publication on acceptance

- support for research data, including large and complex data types

- gold Open Access which fosters wider collaboration and increased citations

- maximum visibility for your research: over $100 \mathrm{M}$ website views per year

At $\mathrm{BMC}$, research is always in progress.

Learn more biomedcentral.com/submissions 